\title{
The Clinical Utility of the Concept of Jing in Chinese Reproductive Medicine
}

\author{
Daniel Maxwell \\ Editor of the Journal of Chinese Medicine
}

\begin{abstract}
The concept of jing is fundamental in Chinese medicine (CM). However, English-language discourse reveals the term to be polysemous, confusing, and contradictory. In the currently flourishing field of Chinese reproductive medicine in the West, clinicians claim to be able to provide treatment for age-related pathologies of the human gametes-ascribed by modern CM to be manifestations of jing - that seem dubious from the perspective of modern biomedicine. Such practitioners reveal scripts that diverge significantly from their biomedical peers. In the context of the unclear modes in which the concept of jing functions, and the emotive sphere of reproductive medicine in which it operates, this paper uses a grounded theory approach to make a thematic analysis of the relevant English-language discourse relating to jing. Interpretive analysis of the resulting themes shows the term being used differently by clinicians and scholars of $\mathrm{CM}$, and that such modes are predicated according to the specific requirements and agendas of the author. Finally, recommendations for clinicians, scholars, and researchers are made along with concluding remarks.
\end{abstract}

\section{Keywords}

Jing, essence, Chinese medicine, eggs, sperm, ovarian reserve, low sperm count, azoospermia

\section{Introduction}

The concept of jing (精, usually translated as 'essence', but left in the Chinese here to allow the term semiotic freedom), is fundamental in CM. Standard core texts used in modern CM education in the $\mathrm{West}^{1}$ tend to present $j i n g$ as part of an established, ahistorical, and internally congruent theoretical framework, in which it constitutes the material foundation of a hierarchy of increasingly subtle and immaterial 'vital substances' that form the building blocks of CM physiology. However, such systematisation flies in the face of scholarship

* An abridged version of this article was published in The Journal of Chinese Medicine, Issue 98 (February 2012). The author would like to thank Professor Volker Scheid, whose sage guidance made the writing of this paper possible, enjoyable, and illuminating.

${ }^{1}$ For example, see Maciocia 2005. 
showing CM to be heterogenous and in constant transformation. ${ }^{2}$ The apparently well-ordered system into which the concept of jing is inserted is far from universal, and authors who look more deeply into the concept find paradox and multiplicity of meaning; ${ }^{3}$ Zhang and Rose, for example, list 22 meanings inherent in the term. ${ }^{4}$ The concept of jing is theoretically problematic: for example, jing is commonly said to be irreplaceable, ${ }^{5}$ and yet many CM texts list 'jing deficiency' as a pattern differentiation for specific diseases 6 especially reproductive dysfunction ${ }^{7}$-and provide acupuncture points ${ }^{8}$ and herbs ${ }^{9}$ that can treat such a disharmony.

When looked at through the prism of reproductive medicine, further questions arise. In the flourishing field of CM fertility treatment in the West, ${ }^{10}$ clinicians posit that $\mathrm{CM}$ treatment can enhance fertility by improving 'egg quality', ${ }^{11}$ sperm count and quality, ${ }^{12}$ and even turn back the 'reproductive clock' of women whose egg supply is — based on laboratory tests - exhausted. ${ }^{13}$ Such clinical results seem unlikely from the perspective of modern biomedicine, which asserts that women are born with all the eggs they will ever have, that gradually decline in quality with age, and that once used up are gone forever. ${ }^{14}$ One might question exactly what $\mathrm{CM}$ clinicians mean by improving 'egg quality' - whether enhancing the general cellular vitality of the gametes or even changing their genetic make-up-and how such claims relate to traditional CM theory. Perhaps there are indeed subtle physiogical variables-as yet undiscovered by Western medicine- that can be influenced by $\mathrm{CM}$ to enhance fertility? Or perhaps the expediency of market forces is leading practitioners to trade on the Oriental mystery that surrounds CM in the West to make unrealistic claims of its clinical potential? Or perhaps naïve Western clinicians are simply reading superlative-but ultimately unrealisticpossibilities into CM theory that were not intended by its authors.

Given that modern biomedical treatment is able to control virtually all aspects of fertility other than the overall quantity and quality of the gametes

\footnotetext{
Andrews 1996; Scheid 2002a; Karchmer 2004.

Hammer 1999.

4 Zhang and Rose 1999.

5 See Flaws 1989 and Ross 1984.

${ }^{6}$ For example, see Maciocia 2005.

Lyttleton 2004; Jin 1999.

8 Deadman et al. 1998.

9 Bensky et al. 2004.

Lyttleton 2004.

Heese 2006; Horne 2011.

${ }_{12}$ Crimmel et al. 2001; Deadman 2008.

${ }^{3}$ Lewis 2004; Horne 2011.

${ }^{14}$ Jones and Lopez 2006.
} 
themselves, practitioners of complementary medicine who claim to be able to influence these factors will be highly sought after by potentially vulnerableand frequently desperate- patients. ${ }^{15}$ The public discourse of such practitioners tends to reject standard biomedical scripts regarding the arbitrary limitations signified by laboratory tests, and instead presents a message of hope backed by a mixture of Chinese and biomedical theory together with unsubstantiated case studies of ageing patients who were able to conceive against the odds with the help of CM. ${ }^{16}$ Given that practitioners of complementary medicine are frequently accused of providing false hope to patients, ${ }^{17}$ it would seem apposite to examine this area of CM to find out how the concept of $j i n g$ is operating.

After presenting the methodology and literature search for this research, a basic orientation is provided that documents a standard modern reading of jing. Then the main themes are described, followed by detailed discussion before concluding comments are made. It should be pointed out that this paper has significant limitations. The author is a Western practitioner of CM who does not read Chinese and this paper is a study of modern Englishlanguage texts written primarily by Western authors. As such any conclusions pertain only to such modern Western discourse, and does not purport to offer a valid assessment of historical Chinese sources.

\section{Methodology}

This paper uses a grounded theory approach ${ }^{18}$ to conduct a thematic analysis of the relevant English-language sources. Thematic analysis is a highly inductive method that facilitates identification, analysis, and interpretation of patterns within data ${ }^{19}$ in order to allow new theories and interpretations to emerge. ${ }^{20}$ It is an inherently flexible method and can be applied across a range of theoretical and epistemological frameworks, and as such is ideally suited for the novice researcher. ${ }^{21}$ In the case of this paper, the relevant data was first identified through a systematic literature search, after which sensitive reading and re-reading of the texts was conducted whilst applying coding to the

\footnotetext{
15 Daniluk 2001; Peterson et al. 2007.

16 Lewis 2011a; Horne 2011.

17 Zollman and Vickers 1999; Ernst 1995.

18 Strauss and Corbin 1990.

19 Aronson 1994.

20 Ezzy 2002.

21 Braun and Clarke 2006.
} 
relevant sections. ${ }^{22}$ The resulting codes were then inductively developed into themes using a reflexive process that involved repeated revisiting of the data and comparison between the different codes and themes. ${ }^{23}$ During this process the following hypothesis emerged from the data: The concept of jing in English-language texts is polysemous, contradictory, and confusing, and there is a lack of congruence between its presentation in the extant historical literature and how it is used in the modern clinical practice of CM.

The identified themes were analysed using an interpretive approach, before being summarised into concluding theories. The epistemological perspective employed is essentially that of social constructivism, which presupposes that CM was - and continues to be-collectively invented and reinvented by various groups at different times. ${ }^{24}$

\section{Literature search}

An online search was made of the following electronic databases:

- PubMed

- AMED

- MEDLINE

- AltHealthWatch

In order to avoid using an unwieldy search algorithm, two separate search algorithms were used as follows:

1) '(jing OR essence) AND (Chinese medicine)': to elicit articles that discuss the concept of jing directly.

2) '(Chinese medicine OR TCM) AND (fertility OR infertility OR reproduct*) AND (sperm OR egg OR ooctye OR ovarian reserve OR premature ovarian failure $\mathrm{OR}$ oligospermia $\mathrm{OR}$ aspermia $\mathrm{OR}$ azoospermia)': to identify papers that discuss the treatment of reproductive disorders associated with the concept of jing.

The searches returned a total of 825 articles. These were initially filtered by title and abstract to exclude irrelevant articles, duplicates, and incorrectly indexed articles. Articles were included where they:

22 Strauss and Corbin 1990

23 Ibid.

24 Kukla 1999. 
- Directly discussed the CM concept of jing.

- Studied reproductive medicine with reference to the CM concept of jing or other related CM concepts (such as the Kidney) or biomedical subjects (such as gametes or genetic factors).

- Contributed to the discourse on jing in other ways by exploring issues of Chinese reproductive medicine, translation, or history.

The sifting process resulted in a total of 18 articles. Additional relevant studies were sought in the reference lists of identified papers, and by searching the online Chinese medicine journals and databases. In order to identify relevant books, an online search was made of the catalogue of the British Library's catalogue; further texts were identified in the bibliographies of these texts, and by manually searching the library of the University of Westminster (London, UK). In addition, in order to examine the discourse around jing in the public domain, an internet search was made using various combinations of the terms 'jing', 'essence', 'gametes', 'ovarian reserve', 'sperm', and 'Chinese medicine'.

The resulting data were found to fit into the following categories:

- Clinical research into the CM treatment of reproductive disease, for example, premature ovarian failure, azoospermia, etc.

- Cultural/sociological/historical discussions of Chinese reproductive medicine.

- Core texts on Chinese medical theory or Chinese reproductive medicine.

- Public-facing websites providing information for potential patients of Chinese reproductive medicine.

A full description of the above search methodology can be found in Appendix 1.

\section{Basic orientation}

The Chinese character for jing, 精, is made up of the significant component $m i$, meaning rice or kernel of grain, and the phonetic component qing, which signifies the colour of lush and vibrant growth and which is thought to contribute to the character's meaning. ${ }^{25}$ Given the supreme importance of rice throughout Chinese history, the image of a lush green rice sprout issuing forth from seed is a culturally compelling symbol of the generative power of life. A

\footnotetext{
25 Wiseman and Zhang 2003.
} 
typical CM taxonomy involves jing being divided into three types: pre-heaven (or 'innate'-said to be formed at conception from the coalescing of the essences of the parents), post-heaven (or 'acquired'-the product of metabolism from eating and breathing), and Kidney jing (which governs growth, development, sexual maturation, reproduction, and pregnancy). ${ }^{26}$ As well as its more abstract meanings, jing also has the narrow meaning of semen. ${ }^{27}$ It should be noted here that, given the focus of this paper on reproductive medicine, the emphasis will be on what is referred to above as 'Kidney jing'. Unfortunately it is beyond the scope of this paper to explore the extensive historical discourse discussing the closely-related doctrines of Mingmen ('life gate'), the Kidneys, and the chong and ren vessels. ${ }^{28}$

Beyond standardised modern readings of $j i n g$, close reading of the literature reveals a tangled web of terms with overlapping meanings and shifting signification. The sample of texts surveyed here reveals a variety of terms, all of which express some aspect of the concept of jing: 'yin essence', 'yang essence', and 'Kidney-qi essence'; 29 'yin jing'; $; 0$ 'jing qi'; ${ }^{31}$ yuan (primal) $q i{ }^{32}$ and 'kidney $q i{ }^{33}$ For Ross, jing is a 'group of overlapping concepts', ${ }^{34}$ and the term is also frequently used in the plural 'essences' ${ }^{35}$ indeed, Dharmananda documents its use to describe any dense physiological fluids (for example, saliva, breast milk, vaginal fluids, etc.). ${ }^{36}$ Even where standardisation and semantic clarity is the primary focus of a text, jing seems to elude simple definition. ${ }^{37}$

\section{Themes}

The following ten themes were identified:

${ }^{26}$ Liang 2003; Maciocia 2005.

27 Zhejiang College of Traditional Chinese Medicine 1995.

${ }_{28}$ See Unschuld 1986; Wu 2010; Hammer 1999.

${ }^{29}$ Hammer 1999.

${ }^{30}$ Lin and Flaws 1991.

31 Zhang and Rose 1999.

32 Furth and Ch'en 1992.

33 Zhejiang College of Traditional Chinese Medicine 1995.

${ }^{34}$ Ross 1984.

${ }^{35}$ Larre and Rochat de la Vallée 1999.

36 Dharmananda n.d.

37 World Health Organisation 2007. 


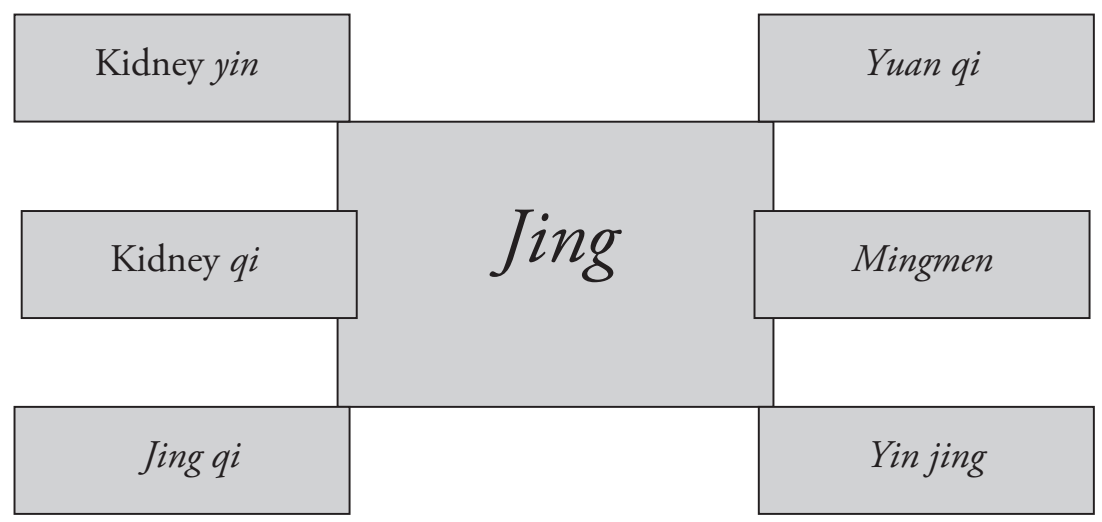

Fig. 1. Various CM terms overlapping with the concept of jing.

\section{Gametes}

A primary theme in the literature is that of jing being used as a direct analogue with the biomedical concept of the gametes. For example, Lyttleton-arguably the most influential Western authority on the CM treatment of infertility and a self-professed exponent of Chinese and Western medicine 'fusion'-boldly states that 'what the doctors in China 2000 years ago were referring to when they described the Kidney Jing is what modern Western medical science refers to as the gametes or eggs and sperm themselves. ${ }^{38}$ In such a reading of $j i n g$, a pattern of jing deficiency corresponds to a pathological lack of eggs or spermpremature ovarian failure or azoospermia, for example-for which a viable clinical strategy is to 'strongly reinforce the Kidney Jing to try and influence the nature of the eggs themselves'. ${ }^{39}$ Whilst appealing in its simplicity and pragmatism, the idea of the narrow correspondence between jing and the gametes is not universal. For example, a modern paper discussing Chinese herbal medicine (CHM) and egg quality does not refer to jing at all. ${ }^{40}$ Clearly, it is not a clinically indispensable concept, even when egg quality and quantity are the primary focus.

\footnotetext{
38 Lyttleton 2004.

9 Lyttleton 2004, p. 373.

40 Heese 2006.
} 


\section{Menstrual blood}

Prior to the twentieth century, practitioners of CM did not know about eggs or sperm, but rather the female analogue to male jing (semen) was menstrual blood. Traditional doctors were aware that when a woman became pregnant, menstruation ceased, and thus deduced-erroneously as we now know- that conception was the result of the coalescing of the male semen and female blood. Unschuld quotes the sixteenth-century author Zhang Huang, 'Man has life because he...has received from his father and mother semen and blood. When [the latter two] contact each other, they unite and congeal to become a fetus in the womb. ${ }^{411}$ The Qing-dynasty gynaecological expert Fu Qingzhu further explains that 'Menstruation is not blood but heavenly water or the tian gui. Originating in the kidneys, it is the essence of consummate yin.... it is red like blood, but it is, in fact, not blood.... People nowadays regard the menstrual flow as blood, but this is an incorrect assumption'. ${ }^{42}$ Such a belief is frequently encapsulated in the pithy phrase 'Menstruation comes from the Kidney', ${ }^{43}$ although modern readings take this to mean that the Kidney governs the hormonal functions of the hypothalamic-pituitaryovarian axis. ${ }^{44}$ Because jing was traditionally viewed as extremely precious, menstruation was viewed as severely depleting, ${ }^{45}$ such that Daoist nuns would practise specific qigong exercises in order to stop menstruation and thus preserve their $j i n g .{ }^{46}$ Regulation of the menstrual cycle was thus of primary importance in traditional women's medicine and seen to have effects far beyond merely reproductive function. ${ }^{47}$ Congruent with this, published cases of infertility tend to show pregnancy occurring as soon as the menstrual cycle has been sufficiently regulated..$^{48}$ However, the view of menstrual blood as a precious manifestation of jing conflicts with other widely-held Chinese folk beliefs that menstrual blood is a superfluous and unclean pollutant, ${ }^{49}$ suggesting that competing scripts have been active through Chinese history.

\footnotetext{
41 Unschuld 2005, p. 52.

42 Yang and Liu 1995, p. 52.

43 Jin 1999 , p. 186.

44 For example, see Geng et al. 2010.

45 Furth and Ch'en 1992.

46 Noll and Wilms 2009, p. 108.

47 Furth 1999.

48 Farquhar 1991.

49 Furth and Ch'en 1992.
} 


\section{DNA and heredity}

Modern authors frequently make a direct correspondence between jing and DNA. For example, in cases of male infertility due to chromosomal abnormality, Lyttleton identifies the causative factor as 'Kidney Jing weakness'. ${ }^{50}$ Such a correspondence is perhaps unsurprising, given that the typical characteristics of jing - 'derived from the parents... provides for a person's constitutional make-up...a fixed substance that cannot be added to or replenished. ${ }^{51}$ — could be just as accurately applied to DNA. Such correspondence is frequently made without acknowledging any semantic or cultural complications: thus for Magidoff 'mutated DNA' is 'changes in the jing' ${ }^{52}$ Damone, on the other hand, exhibits more paradigmatic sensitivity by describing reproductive essence as 'genetic-like'. ${ }^{53}$ Whilst a general thread runs through the literature acknowledging the difficulty of altering the genetic make-up of gametes with CM, a recent study suggests that this may in fact be possible with CHM..$^{54}$ Horne argues that the possible mechanism of this may involve influencing epigenetic components that dictate how genes are expressed throughout the reproductive system. ${ }^{55}$

\section{Developmental stages}

The locus classicus of jing and reproductive theory is undoubtedly the first chapter of the Huang Di Nei Jing Su Wen, in which the seven- and eight-year cycles of females and males are described (see Appendix 2). The 'Tian gui' (also translated as 'Kidney water', or the more opaque 'Heavenly Tenth' by Wiseman and Feng ${ }^{56}$ ) referred to in this chapter is widely understood to refer to jing 'in its role in creating the menstruate, ${ }^{57}$ and is frequently glossed without the semantically difficult 'tian gui' ('essence is responsible for the onset of puberty, fertility and the menopause'). ${ }^{58}$ Thus tian gui describes an essentially temporal process that, where pathological, can be treated via the jing, 'If periods never begin (primary amenorrhoea)... the TCM doctor will treat the

\footnotetext{
50 Lyttleton 2004, p. 262.

51 Liang 2003.

52 Magidoff 2000.

53 Damone 2008.

54 Tempest et al. 2005.

55 Horne 2011.

56 Wiseman and Feng 1998.

57 Liang 2003, p. 7.

58 Betts 2006.
} 
Kidney Jing. ${ }^{59}$ It is noteworthy that in CM the arrival of tian gui is seen to be a virtually identical process in males and females (with minor differences in timing ${ }^{60}$ ), whereas in biomedicine, puberty and the ending of reproductive capacity are governed by fundamentally different physiology. Thus oogenesis begins in females before they are born and continues until 'the pool of remaining ovarian follicles becomes exhausted' in their forties, whilst spermatogenesis starts in males at puberty and 'healthy men...can retain reproductive capacity into their eighties or nineties'. ${ }^{61}$ Such differences call into question the direct commensurability of jing with such biomedical analogues.

\section{Matter and spirit}

Unlike most CM concepts that tend to be processual in focus, ${ }^{62}$ jing easily becomes glossed as a static material form. This probably originates from the the $S u$ Wen statement, 'Essence is the root of the human body. ${ }^{63}$ A modern Chinese textbook subtly distorts this into the more decisively earthbound, 'essence is the material base of the human body' ${ }^{64}$. For Sivin, jing is a 'fundamental substance', for Porkert, it is 'the concrete basis of... individual existence', Damone describes it as a 'raw material' and for Kaptchuk, it is a 'texture' ${ }^{65}$ Thus jing is frequently portrayed as a kind of anabolically-potent source material from which semen, blood, bone marrow, brain, and spinal cord originate, and as such represents the earthly base of a continuum of increasingly subtle physiology that culminates in shen. Such a model matches agreeably for modern sensibilities with scientific distinctions of solid, liquid, and gas (represented by jing, qi, and shen).

However, the conceptual borders of jing are not always so distinct. Although associated with the physical body, Larre and Rochat de la Vallée suggest that 'Essences have no form and no shape. They are the condition of any shape, they are able to make any and every form' ${ }^{6}{ }^{66}$ Damone presents the beguiling theory in this regard that jing represents the stem cells from which all other physical substance and cells are derived ${ }^{67}$ There are clearly dynamic potentials within jing; as Larre and Rochat de la Vallée state, 'Essences are... the ele-

\footnotetext{
59 Lyttleton 2004.

60 Furth 1999.

61 Tortorra and Derrickson 2005, p. 1094.

62 Farquhar 1987.

63 In Deadman et al. 1998.

${ }^{64}$ Cheng 1987.

65 Sivin 1987; Porkert 1974; Damone 2008; Kaptchuk 2000.

${ }^{66}$ Larre and Rochat de la Vallée 1999.

67 Damone 2008, p. 68.
} 
ments or components of life, and life is inside these components' ${ }^{68}$ Horne makes a cogent point of comparison in relation to gametes, which are not inert lumps of cytoplasm (i.e., yin without yang), but are filled with thousands of times more mitochondria than typical human cells ${ }^{69}$ - tiny energy factories which have been found to respond to $\mathrm{CHM}^{70}$ In CM it is of course impossible to have yin physical substance independent of yang: ' $Q i$ can generate essence, and essence can generate $Q i{ }^{\text {' }}{ }^{71}$ Porkert's 'structive potential' is illuminating in this regard-where 'structive' is a complement to the 'active' principle represented by $q i$ and shen, and implies the capacity 'to render concrete, to substantiate, a given effect without regard to its quality'. ${ }^{72}$ Such a reading harks back to chapter eight of the Ling Shu that states, 'The kidney stores essence; essence is the abode of spirit'. This relationship is repeated in chapter 36 of the Nan Jing, where jing is first introduced as the dyad 'spirit-essence' (see Appendix 2). To forget the 'vertical' interpenetration of jing with shen-which modern reductive readings of the term seem to-can have repercussions with regard to fertility treatment, 'A change on the shen level also involves a change on the jing level... in this sense shen facilitates fertility on the physical level. ${ }^{73}$ To this end, modern clinicians of CM frequently emphasise psychoemotional support in their treatment programmes for poor ovarian reserve. ${ }^{74}$

\section{Quantity and decline}

The theme of jing being material in nature is closely associated with it being presented as being restricted in quantity and undergoing continuous declinesomething like a candle burning inexorably down. Indeed, Dharmanda documents the traditional Chinese fears around declining jing recorded in a Ming Dynasty novel that tells the story of a man who dies from sexual indulgence, whose doctor's concluding comment is 'The candle flickers once the oil is used up'. ${ }^{75}$ Thus Flaws states: 'We are each endowed with a certain quantity and quality of this... at the moment of conception and this cannot be augmented or modified. ${ }^{76}$ It is a 'finite bundle ${ }^{77}$ that is either plentiful or scant-such

\footnotetext{
${ }^{68}$ Larre and Rochat de la Vallée 1999.

69 Horne 2011.

70 Leung et al. 2005.

71 Liu and Liu 2009.

72 Porkert 1974.

73 Noll and Wilms 2009, p. 311.

74 Horne 2011; West 2011; Lewis 2004.

75 Dharmanda n.d.

76 Flaws 1989.

77 Lyttleton 2004, p. 338.
} 
that Lyttleton is able to divide its pathological lack into severe, moderate; and mild, each with specific symptoms. ${ }^{78}$ The view that $j i n g$ (as eggs) 'gets used up with the hundreds of menstrual cycles a woman experiences'79 is mirrored by biomedicine's precise numerical formulations: 'at birth, approximately 200,000 to $2,000,000$ primary oocytes remain in each ovary ... and around 400 will mature and ovulate during a women's reproductive lifetime'. ${ }^{80}$ Such temporal diminution of the gametes is also the case for men, 'sperm production decreases $50-70 \%$ between ages 60 and $80{ }^{\prime}{ }^{81}$ The Chinese notion that men lose jing through ejaculation is associated with a long tradition extolling the benefits of sexual abstinence, ${ }^{82}$ so that Chinese doctors frequently advise sexual abstinence in cases of infertility. ${ }^{83}$ Originally it was thought that just excessive sexual activity depleted the jing, but the Qing dynasty doctor Wu Tang (1758-1836) expanded this so that 'all human activity can agitate and disturb the essence'. ${ }^{84}$ However, although such linear temporal decline tallies nicely with the biomedical view of the gametes, it is at odds with the theory that jing is continually augmented by postnatal jing (and thus jing operates metaphorically more like a rechargeable battery than a candle).

Whilst primarily quantitative in nature, discourse on the decline of jing sometimes involves qualitative entropy that is often likened to the damage suffered by DNA in Western theories of reproductive ageing. ${ }^{85}$ Thus Lyttleton reports that 'less than ideal Jing may be inherited if the parents are older than 40 ' ${ }^{86}$ Lyttleton criticises Western artificial reproductive technology (ART) for pursuing quantity at the expense of quality, 'Kidney Jing, that hard-tomeasure quality of inheritance, is being ignored'. Indeed, ART seems to produce male offspring who themselves have compromised reproductive health. ${ }^{87}$ Such understandings have a historical basis in traditional CM-as Wu documents, traditional doctors would blame anomalies, such as hermaphrodite offspring, on the jing. ${ }^{88}$

\footnotetext{
78 Lyttleton 2004, p. 13.

79 Lyttleton 2004.

80 Tortorra and Derrickson 2005, p. 1073.

${ }^{81}$ Tortorra and Derrickson 2005, p. 1094.

82 See Noll and Wilms 2009.

83 Damone 2008.

84 Liu 2005, p. 23.

85 Neal-Perry and Santoro 2006.

86 Lyttleton 2004.

87 Kai et al. 2007; Jensen et al. 2007.

${ }_{88}$ Wu 2010, p. 96.
} 
The clinical utility of the concept of jing ultimately rests on whether clinicians are able to intervene if it is found to be deficient. One of the difficulties in assessing this is that authors tend to present only successful case studies. Liang, for example, documents a 48-year-old perimenopausal woman who, after CM treatment, managed to produce 18 eggs during an IVF cycle and successfully conceive. ${ }^{89}$ Lewis $^{90}$ and Horne ${ }^{91}$ also describe cases where women in their late forties were able to conceive with help from CM. For many authors, jing deficiency is an entirely relevant clinical distinction and 'tonify jing' a viable treatment strategy. ${ }^{92}$ For example, Jin gives 'Excessive consumption of Kidney Essence' as a pattern differentiation for oligospermia, and provides his own formula- 'Jin's decoction for replenishing essence and sperma liquefaction to nourish the Kidney and replenish Kidney essence'.$^{93}$ Lyttleton acknowledges that treatment of jing deficiency requires long-term treatment (over months and years), and asserts her experience of doctors in China providing successful treatment in cases of jing deficiency. ${ }^{94}$ Indeed, numerous clinicians explicitly assert that $\mathrm{CM}$ is able to improve egg quality in cases where biomedicine is unable to help..$^{95}$

Lewis, a high-profile CM reproductive specialist, is at pains to reject typical Western ideas of reproductive ageing and presents her perspective on 'the truth about our eggs', in which 'the ocean of our fertility doesn't dry up; it just becomes still. And with help it can flow once more. ${ }^{96}$ She tends to side step the idea that the body 'runs out' of something (jing/eggs), and instead posits the decline in fertility due to age as being due to 'hormonal balance and blood flow' ${ }^{97}$ It may be that such a view has a historical basis in traditional CM-as Farquhar suggests, 'the discrete transplantable objects of Western medicine... are seen as mere products of powerful processes that govern the life of the body. ${ }^{98}$ Lewis also disputes the effects of ageing on egg quality: 'contrary to what Western medicine would lead us to believe, a woman's eggs do not have an "expiration date" ". ${ }^{99}$ Anecdotal evidence seems to confirm that CHM may indeed be able to restore reproductive capacity, even in relatively severe

89 Liang 2003, p. 79.

90 Lewis 2011a.

91 Horne 2011.

92 Lyttleton 2004; Clavey 2003; Zelicha and Nuria 2010; Zhang 2007.

93 Jin 1999.

94 Lyttleton 2004, p. 119.

95 Heese 2006; Ke 2008; Brown 2009.

96 Lewis 2004, p. 174.

97 Lewis 2004, p. 178.

98 Farquhar 1991.

99 Lewis 2004. 
cases of premature ovarian failure. ${ }^{100}$ Horne boldly supports such a notion ('We can reverse signs of aging until a woman enters the menopause'), and provides treatment protocols that involve 'slowing or reversing oocyte aging' ${ }^{101}$ Such protocols might be seen to be supported by China's long historical tradition of practices designed to prevent or replace the loss of jing, especially from within the Daoist tradition. ${ }^{102}$

Other authors are more careful to avoid the emotionally charged issue of 'turning back the clock' with regard to reproductive capacity. Elliott, for instance, disputes that CM treatment can prevent the affects of ageing on egg quality. ${ }^{103}$ West, a high-profile infertility specialist in the UK, asserts her awareness 'that a woman is born with all the eggs she is ever going to have' but maintains that 'you can improve the environment that the existing eggs are growing in' by using acupuncture to 'help improve blood flow to the ovaries, as this reduces significantly with age'. ${ }^{104}$ Heese initially asserts that CM cannot turn back time and affect egg quality, but is later apparently unable to resist an about-face: 'Whilst it cannot turn back time and improve egg quality in an older woman, it may... indirectly influence its maturity and quality.' ${ }^{105}$ Most authors seem to side-step the contradiction inherent in CM theory-that the gradual depletion of jing is a natural part of ageing but as soon as it becomes a barrier to conceiving it is made pathological. Liang, however, acknowledges this, stating that 'Although this [decline] is a natural stage of a woman's development, for the purposes of achieving pregnancy, it is considered a pathology here'. ${ }^{106}$

\section{Yin and fluids}

Jing is widely associated with yin and fluids: 'Qi belongs to Yang whereas blood and essence belong to Yin' ${ }^{107}$ Hammer clinically tangible evidence supporting this theory: 'Kidney essence is often associated more with Kidney yin than with Kidney yang; partially because on the pulse, deficiency of Kidney yin and Kidney essence have similar qualities (tight and wiry). ${ }^{108}$ Lin and Flaws suggest a broader classification, in which ' $y$ in jing' includes jing, blood,

\footnotetext{
100 Chao et al. 2003.

101 Horne 2011.

102 Xingzhe 2004a.

103 Elliott 2009.

104 West 2011.

105 Heese 2006.

106 Liang 2003.

107 Liu and Liu 2009.

108 Hammer 1999.
} 
and jin ye-all of the fluid aspects of the body. ${ }^{109}$ Elsewhere, however, Flaws equates jing directly with Kidney yin: 'Kidney yin is the jing essence and the substantial aspect of the kidney." ${ }^{110}$ Other authors, however, point out that jing can be seen to be 'before' yin and yang — and thus the origin of both. ${ }^{111}$ For some authors, female sexual secretions are manifestions of jing, ${ }^{112}$ whilst Lyttleton disputes this based on the narrow equation of jing with gametes: 'Since these secretions do not contain gametes, they do not have such a direct connection to the Jing. Rather, they reflect Kidney Yin reserves. ${ }^{.13}$ Historically, some doctors have taken the idea of $j$ ing being a fluid-like material substance to its logical conclusion, leading to various historical arguments regarding the topography of literal 'pathways of essence' connecting the brain, Kidneys, and reproductive organs. ${ }^{114}$ As a sidenote, the herbs that tonify jing in the material medica tend to be warm, sweet, and salty yang tonics, rather than the moist, cool, and sweet medicinals that one might expect to support yin and fluids. ${ }^{115}$

\section{Reproductive strength and constitution}

In CM terms strong jing implies a dyad of robust constitution combined with a high reproductive capacity at both macro and micro levels, so that Lyttleton states that 'Plentiful Jing increases fertility... women who are successful in having babies in their 40 s... often live longer than average' 116 and 'sperm that lack the wherewithal to carry out penetration and fertilisation of egg cells [reflect] quite serious Kidney Jing deficiency.' Wu details that such reproductive strength was traditionally viewed as being intrinsic in the jing itself, such that where male jing dominated it would produce a boy and vice versa. ${ }^{117}$ However, the linear equation 'more jing=greater reproductive potential' might be seen to be challenged by modern studies in which increased frequency of ejaculation actually improves sperm quality and quantity. ${ }^{118}$

\footnotetext{
109 Lin and Flaws 1991.

110 Flaws 1989.

111 Kaptchuk 2000; Hammer 1999; Scheid 2007.

112 Noll and Wilms 2009, p. 29; Guo and Powell 2001, p. 139.

113 Lyttleton 2004, p. 339.

114 Wu 2010.

115 Bensky et al. 2004.

116 Lyttleton 2004, p. 262.

117 Wu 2010, p. 94.

118 Greening 2007; Damone 2008.
} 


\section{Sex and morality}

Because jing is inseparable from reproduction — and therefore sex — traditional Chinese discourse around it unsurprisingly reveals moral scripts. The origins of such sensitivities might be traced back to the $S u W e n$, where Qi Bo explains that, "The people of today... through their lust they exhaust their essence, through their wastefulness they dissipate their true [qi]. ${ }^{.119}$ In a commentary by Wang Bing, he elucidates: 'To make frivolous use [of one's essence] is called "wastefulness." ... it is because the sages cherished [their] essence and carefully considered its use that their bones were full of marrow and strong. ${ }^{.120}$ Thus jing is used as moral currency to make a point about physically weakening effects of licentiousness sex. Such scripts continue to the present day-for Xingzhe 'Sex is worse than tigers or wolves' and 'anything that excites desire, especially sexual desire, disturbs jing... unbridled craving for things is ultimately weakening for the whole society; less essence, less spirit, less will.' ${ }^{121}$ Both quotations reveal a discourse in which jing is the link between frivolous sex and a weakening of the very foundations of the individual body and society. In the case of women, Furth has clearly documented how the depleting effects of female gestational functions were associated with a discourse that emphasised women's fundamental weakness in comparison to men. ${ }^{122}$ Further gendered questions might be asked about how the label for the male seed became synonymous with the generative aspect of life in a patriarchal society. ${ }^{123}$

\section{Depth and density}

Discourse around jing frequently emphasises qualities of depth and density: 'there is a kind of earthly aspect, a density.... Essences are very dense because they are full of life; ${ }^{124}$ 'it is the life spring sourced in our deepest origins... [if] the deficiency is deep, treatment needs to be strong, persistent, and lengthy'. ${ }^{25}$ This is epitomised in the nature of semen, 'sperm.... In the form of a liquid it is nothing other than a very rich and dense possibility of making life'. ${ }^{126}$ Treatment of jing is usually through herbs (rather than acupuncture), in particular

\footnotetext{
119 Unschuld 2003, p. 53.

120 Ibid.

121 Xingzhe 2004a.

122 Furth 1987.

123 Furth 1999.

124 Larre and Rochat de la Vallée 1999.

125 Lyttleton 2004.

126 Larre and Rochat de la Vallée 1999.
} 
herbs that — according to the Nei Jing — have 'affinity for flesh and blood'e.g., animal products. Given that in western countries, such as the UK, animal products are banned, one might question whether it is possible to tonify jing effectively with the remaining available CHMs. Damone quotes Ye Tianshi (1667-1746) in this regard: 'Essence and blood have form. [Therefore do not] use grasses and wood-substances, which lack feeling.... Their qi does not correspond to [essence and blood] '. ${ }^{127}$ Unsurprisingly, given its multiple identities, a variety of words express the effects of herbs on jing. Thus Shan Yao and Tu Si Zi 'secure' jing, Don Chong Xia Cao and Ba Ji Tian 'augment' jing, Shu Di Huang and Lu Rong 'generate' jing, Zhi He Shou Wu 'preserves' jing, E Jiao 'replenishes Kidney' jing, Rou Cong Rong 'enriches' jing and Bu Gu Zhi 'stabilises' jing. ${ }^{128}$ Because Kidney jing is nourished by post-heaven jing, clinicians working in the area of low egg reserve tend to make diet and nutrition a high priority, ${ }^{129}$ frequently employing substances from modern naturopathic nutrition such as wheatgrass, royal jelly, Co-Enzyme Q-10, ${ }^{130}$ algae, and seaweed. ${ }^{131}$ Arguably the quintessential substance to tonify jing is $\mathrm{Zi} \mathrm{He}$ Che (Hominis Placenta), which according to the Commentary on the Divine Husbandman's Classic of Materia Medica, 'tonifies dual deficiency of yin and yang, with the ability to restore the root and return the primal [qi]'. ${ }^{132}$ Assessing the constituents of this substance from a biomedical perspective is revealing, and reads like a primitive combination ART medicine-complete with gonadotropins, estradiol, progesterone, and prolactin - to powerfully activate the endocrine glands.

\section{Discussion}

\section{Historicising jing}

Modern Western clinical texts frequently present $\mathrm{CM}$ as an ahistorical system that was defined millennia ago and has endured without change. ${ }^{133}$ Recent scholarship, however, suggests that CM is 'deeply historical', ${ }^{134}$ and documents

\footnotetext{
127 Damone 2008.

128 All from Bensky et al. 2004.

129 Horne 2011; Lewis 2004.

130 Lewis 2011b.

131 Noll and Wilms 2009.

132 Bensky et al. 2004.

133 Scheid 2002a.

134 Farquhar 1987.
} 
the complexities of its relationship with modern biomedicine. ${ }^{135}$ Modern Chinese reproductive specialists are-by definition-practitioners of 'integrated Chinese-Western medicine', ${ }^{136}$ and as such represent the fruit of the Communist agenda of integration and 'scientisation'. ${ }^{137}$ Liang, for example, epitomises the typical mindset of the modern CM gynaecologist when she states that, 'The Chinese medical concept of the kidneys correspond directly to the endocrine and reproductive systems' 138 (and congruent with such a view Liang supplements the Kidneys in virtually all of her case studies of ageing women). Li similarly elevates the Kidney to a physiological position in andrology: 'Only the kidney is the crucial organ for male infertility... insufficient essence is the fundamental causative factor of male infertility'. ${ }^{139}$ Modern Western 'specialists' in the field of Chinese reproductive medicine, of course, learnt their trade since biomedicine arrived so forcefully in China, and unsurprisingly therefore tend to stick close to the modern 'party line' of integration, such that CM concepts and theory remain congruent with biomedicine. ${ }^{140}$

At some point during the twentieth century, CM had to grapple with the reality of eggs and sperm (first discovered by the seventeenth-century European biologist Leeuwenhoek $)^{141}$-and the derision from some quarters that it did not know about them. ${ }^{142}$ Farquhar has documented the pressure exerted on CM during the late twentieth century to come up with similar tangible entities to those recently discovered by biomedicine (e.g., bacteria, viruses, gametes, etc.). ${ }^{143}$ Fortunately, representatives of $\mathrm{CM}$ were able to save face by pointing out the correspondence of the gametes with jing, simultaneously proving that $\mathrm{CM}$ was way ahead of its time. As a happy coincidence, polarising the focus of conception around jing (and thus the Kidneys) meant that the potentially humiliating theory that semen unites with female blood at conception could be allowed to fade into obscurity.

It is of course not an entirely modern occurrence to gloss jing as a physical object (whether 'the body' or 'gametes') —-this has a historical basis in its alternative identity as semen. Whilst it is impossible to verify how the pre-Han originators of $\mathrm{CM}$ conceived of jing, one might imagine that despite their

\footnotetext{
135 Andrews 1996; Karchmer 2004.

136 Karchmer 2004.

137 Andrews 1996; Karchmer 2004.

138 Liang 2003.

139 Li 2005.

140 For example, see Lyttleton 2004; Marchment 2007.

141 Magner 2005.

142 Andrews 1996.

143 Farquhar 1987.
} 
primary focus on process, resonance, and relationship, ${ }^{144}$ they still had to somehow classify the physical 'stuff' of the human body-physicality that visibly suffered inexorable temporal decline, with an associated deterioration in reproductive capacity. It may be that jing fitted as a descriptor of the 'body' in this regard.

For modern clinicians, who tend to tread a path somewhere between CM and biomedicine, considering jing as 'the refined part of all the $q i$ in the universe [and] all the useful entities within the human body' eludes clinical utility. ${ }^{145}$ Practitioners are required to make clinical decisions, and jing is therefore required to take on the identity of a physical substance that can be present or deficient in discrete amounts and thereby influenced through treatment. Such narrow readings, however, exhibit the common tendency to edit out the contradictions and anomalies that do not fit one's own agenda when assembling a coherent version of another culture's medicine. ${ }^{146}$ Thus for modern clinicians the scope of jing identified in the themes above-that includes aspects of form, function, and process-becomes restricted in the interests of clinical expediency.

Historians and philosophers, on the other hand, tend to allow jing a broader scope of meaning, asserting that to conceive of it as a fixed physical entity is anathaema to CM, as jing is by definition in a process of continuous movement and transformation. ${ }^{147}$ For a medicine that assumes 'transformation as the inalterable condition of being...' Farquhar argues, '... essences that are permanent... are not issues for discourse'. ${ }^{148}$ Just as clinicians require jing to assume an identity with which they can work, it is the job of the scholars to allow the manifold meanings of jing to shine. Historians and philosophers, of course, invariably read classical Chinese, and thus may be able to embrace multiple semantic subtleties, whilst modern clinicians may have to settle for the meaning appropriate to the matter at hand-in the case of reproductive medicine, the gametes (although it should be noted that modern Chinese practitioners seem to share equally narrow readings of the term). However, Wu argues against the tendency of scholars to disproportionably privilege CM medical scripts of function ('vital flows and transformation') over form ('the physical bodily space'), identifying both as forming a vital tension in the discourse of traditional doctors of CM. ${ }^{149}$

\footnotetext{
144 Ibid.

145 Zhang and Rose 1999.

146 Farquhar 1987.

147 Larre and Rochat de la Vallée 1999.

148 Farquhar 1987.

149 Wu 2010.
} 
That the term jing defies straightforward linguistic capture in English should come as no surprise. Translation of CM is highly problematic ${ }^{150}$ as there is invariably no one-to-one correspondence between English and Chinese words ${ }^{151}$ and Chinese meaning tends to operate contextually. ${ }^{152}$ Add to this the semiotic consideration that the concept of $j i n g$ is suspended in dense cultural 'webs of significance', ${ }^{153}$ one is left with the essential 'untranslatability' of $j i n g .{ }^{154}$

Meaning in $\mathrm{CM}$ tends to be inherently flexible. Hsu has pointed out that classical CM education teaches 'different meanings in particular contexts' and points out 'the basic rule for reading classical Chinese texts- that what was valid in one context was not in another'. ${ }^{155}$ Unlike biomedicine, such polysemy is not viewed as problematic in CM: 'The senior doctor Zhang made no attempt whatsoever to try to reconcile these different meanings'. ${ }^{156}$ The Western translators of CM seem to continue such a tradition. Lyttleton, for instance, initially glosses jing as gametes, but without any overt acknowledgement or signposting jing comes to represent 'the potential for gamete development' (rather than the gamete itself), 'the function of the ovaries and some aspects of pituitary function', and one of 'the "nutrients" required for an egg to develop. ${ }^{157}$ The term thus moves from form to function and object to process, demonstrating significant semantic fluidity.

For some, such flexibility captures the overlapping holistic nature of reality and exposes the falsehood in the tendency of science to present reality in terms of immutable objects and fixed meanings. For others, however, it exposes CM as an example of what Karl Popper defined as pseudo-science. ${ }^{158}$ In this view, the principles of CM, like Marxism or Freudian psychoanalytic theory, can be made to explain any clinical data whatsoever and are thus unfalsifiable-and therefore unscientific. Such semantic fluidity in the hands of CM authors is frequently extrapolated cross-paradigm, allowing them to be inappropriately (from the scientific perspective) creative with biomedical 'facts' (see below).

The concept of jing thus eludes straightforward definition in English, and its scope goes beyond a label for any particular physical structure—as Bromley et al., point out, 'Jing is both adjective and noun, vital and vitality, essence and

\footnotetext{
150 AAOM 2006.

151 Buck et al. 2000.

152 Bensky et al. 2006.

153 Geertz 1973.

154 Kovacs 1989.

155 Hsu 1999.

156 Ibid.

157 Lyttleton 2004.

158 Okasha 2002.
} 
essential'. ${ }^{159} \mathrm{Hsu}$ creatively bridges such linguistic shortcomings by coining the composite term 'substance-force' to describe jing. ${ }^{160}$ The concept of jing thus includes aspects of form/substance and function/process. Just like the seed of a plant, jing is at once a spatial object as well as being the potential of other future forms. Whilst not 'alive' in the same way as the grown plant, a seed remains dormant, awaiting activation by the right conditions. Similarly, jing is rooted in the physical, but its primary raison d'etre is of future generation and enfoldment.

\section{Jing and clinical practice}

What are clinicians to do with such confusion? One might follow the example of Professor Li Yueqing, a modern CM andrologist, who so fully embraces the clinical relevance of semen analysis that for him 'neither the patient's selfsensation... nor his tongue show us any reliable signs... the microscopic examinations are the only way to make differentiation'. ${ }^{161}$ Or one may agree with Farquhar and resist such modern distortion of CM theory: 'Chinese medical thinking is not naturally murky, it just gets that way when one attempts to fill its intellectual objects (patterns of pathological function) with anatomical content'. ${ }^{162}$ Professor Li's bold statement points to a very modern problem - that ever since Chinese doctors were able to look through a lens at sperm (or indeed at eggs or ovaries), it became clear that not all patients with infertility show explicit signs of the 'Kidney deficiency with insufficient essence' that for Professor Li constitute the 'fundamental causative factor of male infertility'. ${ }^{163}$ However they think about them, modern CM practitioners working in reproductive medicine face a barrage of biomedical test results proffered by increasingly well-informed patients who expect their practitioner not only to understand them, but also to intervene successfully in order to influence them. Such tests have become the standard method to assess the effects of CM treatment modern reproductive research. ${ }^{164}$ As a practitioner, one might welcome the advantages provided by such clinical information, and respond by improvising an 'integrated' diagnosis and treatment. ${ }^{165}$ Indeed, one perspective on what has happened to CM since the arrival of biomedicine

\footnotetext{
159 Bromley et al. 2010.

160 Hsu 1999.

161 Li 2005.

162 Farquhar 1991.

163 Li 2005.

164 For example, see Geng et al. 2010.

165 For example, see Elliott 2009; Zelicha and Nuria 2010.
} 
in China is that, rather than distortion, such integrative improvisation represents innovation. ${ }^{166}$ Now that CM finds itself in the post-genomic era, practitioners of $\mathrm{CM}$ are frequently required to respond to new discoveries. Horne, for example, presents innovative theories regarding epigenetics, even suggestingcontentiously - that a woman's body may even be able to produce fresh eggs. ${ }^{167}$

There are, however, dangers associated with attaching CM so closely to biomedicine, as recently persuasively documented by Scheid in the case of menopause. ${ }^{168}$ To downgrade empirical clinical knowledge built over centuries in favour of the tangible presence of 'jing' as seen through a microscope risks losing potentially effective-albeit at times theoretically precariousclinical strategies that had developed prior to the paradigm shift. For instance, the shift in women's reproductive medicine from focusing primarily on the blood (as jing) to focusing more on the eggs (as jing) entails changing the primary clinical strategy from nourishing blood to nourishing jing. Such theoretical complications are not unique in $\mathrm{CM}$; in some ways this mirrors the long-running debate in Chinese medicine about the respective roles of the Heart and brain in terms of housing the shen (spirit), where new theories simply began to coexist with-rather than replace-the old theories. ${ }^{169}$ Such 'grafting' of the new on to the old is typical of the development of CM. ${ }^{170}$

\section{Double standards}

The discourse of modern practitioners of CM is apparently very different to their biomedical peers, who at times brutally pronounce ${ }^{171}$ on a woman's reproductive capacity based on clinical tests, despite these tests having a modest-to-poor predictive capacity. ${ }^{172}$ Lewis states that biomedicine 'can do little to help' in cases of premature ovarian failure, whilst for the CM practitioner the condition is 'rewarding', backing up this assertion with the polemic force of a patient diagnosed as 'irreversibly infertile' by her Western medicine doctor who was helped to conceive with CM. ${ }^{173}$ Lewis markets her services to a client group that biomedical consultants would view as irremediably infertile and beyond even the help of ART, so that women 'whose FSH values are well

\footnotetext{
166 Karchmer 2004.

167 Horne 2011.

168 Scheid 2007; Scheid 2009.

169 See Deadman et al. 1998 , p. 533.

170 Andrews 1996.

171 Lewis 2004; Atwood and Dobkin 1992.

172 Broekmans et al. 2006.

173 Lewis 2004, p. 239.
} 
over $100 \ldots$ [and] ... whose AMH values were zero conceive naturally'. ${ }^{174}$ To such patients a diagnosis of jing deficiency is potentially less terrifying than 'ovarian failure' for both patient and practitioner, especially given the existence of herbs and acupuncture points that - theoretically at least-increase jing. Lewis rejects the biomedical view of the reproductive system as an 'everdeteriorating disease process waiting for intervention' and instead views it through the 'different lens' of Chinese medicine, in which the body-mindspirit is imbued with 'miraculous' abilities and the overall context is given as, 'There's no such thing as infertility'. ${ }^{175}$ Despite reframing pathology through a 'different lens', however, Lewis' descriptions of the reproductive system remain cast in biomedical terms: 'FSH is the flame. The uterus is the oven. $\mathrm{LH}$ is the opening of the flue. The ovaries are the wood. ${ }^{176}$ This displays the tendency of practitioners of CM to cherry-pick from biomedical theory when it suits their purposes-thus the title of Lewis' book, The Infertility Cure, ${ }^{177}$ is couched in biomedical terms, and her discourse about infertility is replete with biomedical explanations of the pathomechanisms involved, thus conferring biomedical authority on her work. Despite her frequent rejections of biomedical discourse, however, her CM is informed by the same questionable biomedical scripts identified in recent scholarship by Scheid:178 'menopausal symptoms can be alleviated when the Kidney system is tonified or stimulated, thus augmenting the Essence. ${ }^{179}$

\section{Conclusions}

This paper demonstrates that the term jing is used in a variety of ways across modern English-language sources according to the specific context and particular agenda of the author. This supports Hsu's contention that 'Different contexts of social practice have been shown to modify the connotation, pragmatic use, and performative significance of Chinese medical terms'. ${ }^{180}$ Not only is the term polysemous in itself, it is associated with a tangle of overlapping terms that are used interchangeably and inconsistently. In light of these issues, this paper puts forward the following conclusions and recommendations:

\footnotetext{
174 Lewis $2011 \mathrm{~b}$.

175 Lewis 2011a.

176 Ibid.

177 Lewis 2004.

178 Scheid 2007; Scheid 2009.

179 Lewis 2004, p. 30.

180 Hsu 1999.
} 
- Clinicians should be aware that glossing jing as the human gametes, whilst clinically pragmatic, narrows the concept to become congruent with modern biomedical scripts. In particular, such a reading loses the functional/ processual aspects of the term, as well as the vital 'vertical' relationship of jing with shen that is potentially significant in terms of treatment. This paper therefore concurs with Farquhar, that 'To give both Chinese and Western medicine their due requires finer discriminations of the specific relations between objects and processes, products and relations of production, spatial and temporal materialities. ${ }^{181}$

- Although the comparison of CM with biomedicine should be approached cautiously, due to unequal underlying power relations, the correspondence of jing with gametes, DNA, and stem cells is alluring. ${ }^{182}$ Investigating the effects of traditional CM jing-strengthening strategies on such possible biomedical correlates of $j i n g$ constitutes a potentially fertile field of research. In terms of reproductive medicine this may involve investigating the effects of acupuncture and CHM strategies to augment jing and strengthen the Kidneys for conditions of low egg reserve, premature ovarian failure, azoospermia, and high DNA fragmentation, amongst others. Given the lack of biomedical options available for poor egg/embryo quality and high sperm DNA fragmentation rates, ${ }^{183} \mathrm{CM}$ strategies to tonify jing may be able to assist childless couples affected by such conditions, and therefore warrants further research.

- The conceptual boundaries between jing and other technical terms within $\mathrm{CM}$ — such as the Kidney—are indistinct. Scholarship to investigate how such distinctions operate, particularly within pre-Han and Han primary medical texts, would be valuable in this regard.

- Authors of CM texts should be vigilant of the limitations of the English language and the western dualistic mindset when dealing with the concept of jing, and take responsibility for clarifying their particular reading of the term. It is recommended that the term be left in its original Chinese to allow for semiotic freedom.

This paper concludes by reiterating the metaphor conveyed to Farquhar by her Chinese teacher, in which classic texts of CM are likened to the bamboo that is flexible enough to be made into both a toothpick and a house. ${ }^{184}$ The

\footnotetext{
181 Farquhar 1991.

182 Karchmer 2004.

183 Carrell and Peterson 2010.

184 Farquhar 1987.
} 
concept of jing shares such conceptual flexibility, and clinicians, scholars, and researchers should remain mindful of this.

\section{References}

AAOM 2006, Asian Medical Nomenclature Debates, Sacramento: AAOM.

Andrews, B. J. 1996, 'The Making of Modern Chinese Medicine, 1895-1937', PhD Dissertation, Cambridge: Gonville and Caius College.

Aronson, J. 1994, 'A Pragmatic View of Thematic Analysis', The Qualitative Report, 2 (1), available from: <http://www.nova.edu/ssss/QR/BackIssues/QR2-1/aronson.html> [Accessed 21 May 2011].

Atwood, W. and Dobkin, S. 1992, 'Storm Clouds are Coming: Ways to Help Couples Reconstruct the Crisis of Infertility', Contemporary Family Therapy, 14 (5): 385-403.

Baker, G. and Morris, K. J. 1996, Descartes' Dualism, London: Routledge.

Bensky, D., Gamble, A., Clavey, S. et al. 2004, Materia medica: Chinese Herbal Medicine, 3rd edition, Seattle: Eastland Press.

Bensky, D., Blalack, J., Chase, C. et al. 2006, 'Toward a Working Methodology for Translating Chinese Medicine', The Lantern, 3 (3): 10-16

Betts, D. 2006, The Essential Guide to Acupuncture in Pregnancy \& Childbirth, Hove: Journal of Chinese Medicine Press.

Boyatzis, R. E. 1998, Transforming Qualitative Information: Thematic Analysis and Code Development, Thousand Oaks, CA: Sage Publications.

Braun, V. and Clarke, V. 2006, 'Using Thematic Analysis in Psychology', Qualitative Research in Psychology, 3: 77-101.

Broekmans, F. J., Kwee, J., Hendriks, D. J. et al. 2006, 'A Systematic Review of Tests Predicting Ovarian Reserve and IVF Outcome', Human Reproduction Update, 12 (6): 685-718.

Bromley, M., Freeman, D., Hext, A. et al. 2010, Jing shen: A translation of Huainanzi chapter 7 , London: Monkey Press.

Brown, L. 2009, Yangsheng: Nourish Life. Available from: <http://www.acubalance.ca/fertilitydiet/acubalance-fertility-diet/yangsheng-nourish-life> [Accessed 21 May 2011].

- 2011, Repeated Unsuccessful IVF Cycles and Diminished Ovarian Reserve-how Chinese Medicine Provides Hope. Available from: <http://acubalance.ca/repeated-unsucessfulivf-cycles-and-diminished-ovarian-reserve-how-chinese-medicine-provides-hope> [Accessed 14 June 2011].

Buck, C., Rose, K., Felt, R. 2000, 'On Terminology and Translation', Journal of Chinese Medicine, 63: 38-52.

Carrell, D. T. and Peterson, M. (eds.) 2010, Reproductive Endocrinology and Infertility: Integrating Modern Clinical and Laboratory Practice, New York: Springer.

Chao, S. L., Huang, L. W., Yen, H. R. 2003, 'Pregnancy in Premature Ovarian Failure after Therapy using Chinese Herbal Medicine', Chang Gung Medical Journal, 26 (6): 449-52.

Cheng, X. N. 1987, Chinese Acupuncture and Moxibustion, Beijing: Foreign Languages Press.

Clavey, S. 2003, 'Notes on the Treatment of Male Infertility', Journal of Chinese Medicine, 73: $45-52$.

Crimmel, A. S., Conner, C. S., Monga, M. 2001, 'Withered yang: A Review of Traditional Chinese Medicine Treatment of Male Infertility and Erectile Dysfunction', Journal of Andrology, 22 (2): 173-82.

Damone, B. 2008, Principles of Chinese Medical Andrology, Boulder: Blue Poppy Press. 
Daniluk, J. C., 2001, The Infertility Survival Guide, Oakland, CA: New Harbinger Publications.

Deadman, P. 2008. 'The Treatment of Male Subfertility with Acupuncture, Journal of Chinese Medicine, 88: 5-16.

Deadman, P., Al-Khafaji, M., Baker, K. 1998, A Manual of Acupuncture, Hove: Journal of Chinese Medicine Publications.

Dharmananda, S. no date, Kidney Water. Available from: http://www.itmonline.org/5organs/ kidney.htm [Accessed 13 June 2011].

Elliott, D. 2009, 'The Treatment of Elevated FSH Levels with Chinese Medicine', Journal of Chinese Medicine, 91: 5-11.

Ernst, E. 1995, 'Complementary Medicine: Common Misconceptions', Journal of the Royal Society of Medicine, 88 (5): 244-7.

Ezzy, D. 2002, 'Qualitative Analysis: Practice and Innovation', Crows Nest, Australia: Allen \& Unwin.

Farquhar, J. 1987, 'Problems of Knowledge in Contemporary Chinese Medical Discourse', Social Science and Medicine, 24: 1013-21.

- 1991, 'Objects, Processes, and Female Infertility in Chinese Medicine', Medical Anthropology Quarterly, 5 (4): 370-99.

Flaws, B. 1989, Endometriosis, Infertility and Traditional Chinese Medicine, Boulder: Blue Poppy Press.

_. 1993, Fulfilling the Essence: A Handbook of Traditional Contemporary Chinese Treatments for Female Infertility, Boulder: Blue Poppy Press.

Furth, C. 1987, 'Concepts of Pregnancy, Childbirth, and Infancy in Chi'ing Dynasty China', The Journal of Asian Studies, 46 (1): 7-35.

- 1999, 'A Flourishing Yin: Gender in China's Medical History', 960-1665, Berkeley, CA: University of California Press.

- and Ch'en, S. 1992, 'Chinese Medicine and the Anthropology of Menstruation in Contemporary Taiwan', Medical Anthropology Quarterly, 6 (1): 27-48.

Geertz, C. 1973, 'Thick Description: Toward an Interpretive Theory of Culture', The Interpretation of Cultures: Selected Essays, New York: Basic Books.

Geng, S. S., Li, H. Z., Wu, X. K. et al. 2010, 'Effect of wujijing Oral Liquid on Menstrual Disturbance of Women', Journal of Ethnopharmacology, 128 (3): 649-53.

Greening, D. 2007, 'Frequent Ejaculation. A Pilot Study of Changes in Sperm DNA Damage and Semen Parameters using Daily Ejaculation', Fertility and Sterility, 88 (1): 19-20.

Guo, B. and Powell, A. 2001, Listen to your Body: The Wisdom of the dao, Hawaii: University of Hawaii Press.

Hammer, L. 1999, 'The Paradox of the Unity and Duality of the Kidneys according to Chinese Medicine: Kidney Essence, yin, yang, qi, the mingmen - Their Origins, Relationships, Functions and Manifestations', American Journal of Acupuncture, 27 (3\&4) available from; <http:// www.dragonrises.edu/wp-content/themes/dragon/downloads/articles/hammer-kidneyduality.pdf> [Accessed 13 June 2011].

Heese, I. 2006, 'The Egg Factor: Using Chinese Herbal Medicine to Improve Egg Quality in a 45-year-old Woman', Journal of Chinese Medicine, 82: 36-41.

HFEA 2008, Fertility Facts and Figures, London: Human Fertilisation and Embryology Authority.

Horne, B. 2011, Optimising Ovarian Reserve. Available from: <http://prodseminars.adobe connect.com/p21685638/?launcher $=$ false\&fcsContent $=$ true\&pbMode $=$ normal $>$ [Accessed 13 June 2011].

Hsu, E. 1999, The Transmission of Chinese Medicine, Cambridge: Cambridge University Press.

Jensen, T. K., Jørgensen, N., Asklund, C. 2007, 'Fertility Treatment and Reproductive Health of Male Offspring: A Study of 1,925 Young Men from the General Population', American Journal of Epidemiology, 165: 583-90. 
Jin, W. X. 1999, Diagnosis of Sterility and its Traditional Chinese Medicine Treatment, Jinan: Shandong Science and Technology Press.

Jones, R. E., and Lopez, K. H. 2006, Human Reproductive Biology, 3rd edition, Amsterdam: Academic Press.

Kai, C. M., Main, K. M., Andersen, A. N. et al. 2007, 'Reduced Serum Testosterone Levels in Infant Boys Conceived by Intracytoplasmic Sperm Injection', Journal of Clinical Endocrinology and Metabolism, 92: 2598-603.

Kaptchuk, T. 2000, Chinese Medicine: The Web that has no Weaver, London: Rider.

Karchmer, E. I. 2004, Orientalizing the Body: Postcolonial Transformations in Chinese Medicine, Ann Arbor, MI: UMI.

Ke, S. K. 2008, 'Treating Infertility in Traditional Chinese Medicine', European Journal of Oriental Medicine, 6 (1): 10-11.

Kovacs, J. 1989, 'Linguistic Reflections of the Translation of Chinese Medical Texts', in Unschuld, P. ed., 1989, Approaches to Chinese Medical Literature, Boston: Kluwer Academic Publishers, 85-96.

Kukla, A. 1999, Social Constructivism and the Philosophy of Science, London: Routledge.

Larre, C. and Rochat de la Vallée, E. 1999, Essence Spirit Blood and Qi, London: Monkey Press.

- 2002, 'Jing Essence', European Journal of Oriental Medicine 4(1), Available from: http:// www.ejom.co.uk/vol-4-no-1/featured-article/jing-essence.html> [Accessed 13 June 2011].

Leung, H. Y., Chiu, P. Y., Poon, M. K. T. et al. 2005, 'A yang-invigorating Chinese Herbal Formula Enhances Mitochondrial Functional Ability and Antioxidant Capacity in Various Tissues of Male and Female Rats', Rejuvenation Research, 8 (4): 238-47.

Lewis, R. 2004, The Infertility Cure, London: Little, Brown and Company.

—. 2011a, High FSH. Available from: <http://thefertilesoul.com/chinese_medicine/> [Accessed 13 June 2011].

—. 2011b, AMH—what does it really mean? (part 1). Available from: <http://thefertilesoul .com/chinese_medicine/> [Accessed 13 June 2011].

Li, H. S. 2005, 'Prof. Li Yueqing's Experience in Treating Male Infertility', Journal of Traditional Chinese Medicine, 25 (2): 122-4.

Liang, L. F. 2003, Acupuncture \& IVF: Increase IVF Success by 40-60\%, Boulder: Blue Poppy Press.

Lin, A. and Flaws, B. 1991, The Dao of Increasing Longevity and Conserving One's Life: A Handbook of Traditional Chinese Geriatrics and Chinese Herbal Patent Medicines, Boulder: Blue Poppy Press.

Liu, F. W. 1998, Trans. by Shuai X. Z. and Flaws, B., The Essence of Liu Feng-wu's Gynecology, Boulder: Blue Poppy Press.

Liu, G. H. 2005, Warm Pathogen Diseases: A Clinical Guide, Seattle: Eastland Press.

Liu, Z. and Liu, L. 2009, Essentials of Chinese Medicine, London: Springer.

Lyttleton, J. 2004, Treatment of Infertility with Chinese Medicine, Edinburgh: Churchill Livingstone.

Maciocia, G. 1999, Obstetrics \& Gynecology in Chinese Medicine, Edinburgh: Churchill Livingstone.

- 2005, The Foundations of Chinese Medicine. A Comprehensive Text for Acupuncturists and Herbalists, 2nd edition, Edinburgh: Churchill Livingstone.

Magidoff, A. 2000, 'In Search of a Philosophical Medicine', California Journal of Oriental Medicine, 11 (2): 29-33.

Magner, L. N. 2005, A History of the Life Sciences, 3rd edition, New York: Marcel Dekker, Inc.

Marchment, R. 2007, Gynaecology Revisited, Sydney: Churchill Livingstone.

Neal-Perry, G. and Santoro, N. F. 2006, 'Aging in the Hypothalamic-pituitary-ovarian Axis', in Neill, J. D., Knobil \& Neill's Physiology of Reproduction, St Louis: Elsevier, 2729-58. 
Noll, A. A. and Wilms, S. 2009, Chinese Medicine in Fertility Disorders, Stuttgart: Thieme.

Okasha, S. 2002, Philosophy of Science. A very short introduction, Oxford: Oxford University Press.

Peterson, B. D., Newton, C. R., Feingold, T. 2007, 'Anxiety and Sexual Stress in Men and Women Undergoing Infertility Treatment', Fertility \& Sterility, 88 (4): 911-14.

Porkert, M. 1974, The Theoretical Foundations of Chinese Medicine, Cambridge, MA: MIT Press.

Qian, H. M., Fan, X. Y., Chen, Y. Y. 2010, 'Dr Chen Ying-yi's Experience in Treating Premature Ovarian Failure', Journal of Traditional Chinese Medicine, 30 (3): 217-21.

Qian, Z. Y. 1997, 'Male Infertility: Three Cases Treated by Acupuncture', Journal of Chinese Medicine, 53: 26-7.

Ross, J. 1984, Zang Fu. The Organ Systems of Chinese Medicine, Edinburgh: Churchill Livingstone.

Scheid, V. 2002a, 'Remodeling the Arsenal of Chinese Medicine: Shared Pasts, Alternative Futures', Annals of the American Sociological Association: Global Perspectives on Complementary and Alternative Medicine, 583: 136-59.

- 2002b, Chinese Medicine in Contemporary China: Plurality and Synthesis, Durham: Duke University Press.

— 2007, 'Traditional Chinese Medicine-What are we Investigating? The Case of Menopause', Complementary Therapies in Medicine, 15 (1): 54-68.

- 2009, 'Globalising Chinese Medical Understandings of Menopause', East Asia Science, Technology and Society: An International Journal, 2 (4): 485-96.

Scheid, V., Bensky, D., Ellis, E., et al. 2009, Formulas \& Strategies, 2nd edition, Seattle: Eastland Press.

Sivin, N. 1987, Traditional Medicine in Contemporary China, Michigan: University of Michigan Centre for Chinese Studies.

Strauss, A., and Corbin, J. 1990, Basics of Qualitative Research: Grounded Theory Procedures and Techniques, Newbury Park, CA: Sage Publications, Inc.

Tempest, H. G., Homa, S. T., Zhai, X. P. et al. 2005, 'Significant Reduction of Sperm Disomy in Six Men: Effect of Traditional Chinese Medicine?', Asian Journal of Andrology, 7 (4): 419-25.

Tortora, G. J. and Derrickson, B. H. 2005, Principles of Anatomy and Physiology, 11th edition, Chichester: John Wiley \& Sons.

Unschuld, P. U. 1985, Medicine in China: A History of Ideas, Berkeley: University of California Press.

—. 1986, Nan ching: The Classic of Difficult Issues, Berkeley: University of California Press.

—. 2003, Huang di nei jing su wen: Nature, Knowledge, Imagery in an Ancient Chinese Medical Text, Berkeley: University of California Press.

- 2005, Chinese Life Sciences. Traditional Readings in Classical Chinese Medicine, Berkeley: University of California Press.

West, Z. 2011, AMH, DHEA, help!! Available from: <http://www.zitawest.com/blog/category/ low-ovarian-reserve/> [Accessed 13 June 2011].

Wing, T. A. and Seidlmeier, E. S. 2006, 'Measuring the Effectiveness of Chinese Herbal Medicine in Improving Female Infertility', Journal of Chinese Medicine, 80: 22-8.

Wiseman, N. and Feng, Y. 1998, A Practical Dictionary of Chinese Medicine, Brookline: Paradigm Publications.

Wiseman, N. and Zhang, Y. H. 2003, Chinese Medical Characters, vol. 1, Basic Vocabulary, Brookline: Paradigm Publications.

World Health Organisation 2007, WHO International Standard Terminologies on Traditional Medicine in the Western Pacific Region, Manila: World Health Organisation. 
Wu, Y. L. 2010, Reproducing Women: Medicine, Metaphor, and Childbirth in Late Imperial China, Berkeley: University of California Press.

Xingzhe, X. Y. 2004, 'Nourishing Life', The Lantern, 1(1), Available from: <http://www.the lantern.com.au/resource_detail.php?id=19> [Accessed 13 June 2011].

—. 2004a, 'Yang sheng: The Thing about jing', The Lantern, 1(2), Available from: http:// www.thelantern.com.au/resource_detail.php?id=55 [Accessed 13 June 2011].

Xutian, S., Zhang, J. and Wozniak L. 2009, 'New Exploration and Understanding of Traditional Chinese Medicine', American Journal of Chinese Medicine, 37 (3): 411-26.

Yang, S. Z and Liu, D. W. 1995, Fu Qing-zhu's Gynecology, Boulder: Blue Poppy Press.

Zelicha, K. and Nuria, U. 2010, 'Poor Ovarian Reserve and High FSH Levels', The Lantern, 7 (2): 6-10.

Zhang, H. H. and Rose, K. 1999, Who Can Ride The Dragon? An Exploration of the Cultural Roots of Traditional Chinese Medicine, Brookline: Paradigm Publications.

Zhang, L. 2007, 'Dr Shi Hanzhang's Experience in Treating Andropathy', Journal of Traditional Chinese Medicine, 27 (4): 284-7.

Zhejiang College of Traditional Chinese Medicine trans. Zhang, T. L. and Flaws, B., 1995, A Handbook of Traditional Chinese Gynecology, Boulder: Blue Poppy Press.

Zollman, C. and Vickers, A. 1999, 'Complementary Medicine and the Patient', British Medical Journal, 319: 1486. 


\section{Appendices}

Appendix 1: Detailed search strategy

\begin{tabular}{llll}
\hline Database & Search terms & $\begin{array}{l}\text { Date of } \\
\text { search }\end{array}$ & $\begin{array}{l}\text { Total results } \\
\text { (articles included) }\end{array}$ \\
\hline PUBMED 1 & $\begin{array}{l}\text { (Chinese medicine } \\
\text { OR TCM) AND }\end{array}$ & & $\begin{array}{l}\text { 210 (Li 2005; Chao } \\
\text { et al. 2003) }\end{array}$ \\
& (fertility OR & \\
& infertility OR & & \\
& reproduct*) AND & & \\
& (sperm OR egg & & \\
& OR ooctye OR & & \\
& ovarian reserve & & \\
& OR premature & & \\
& ovarian failure & & \\
& OR oligospermia & & \\
& OR aspermia OR & & \\
& azoospermia) & & \\
& $($ jing or essence) & & \\
AND Chinese & & \\
PUBMED 2 & medicine
\end{tabular}

184 (Tempest et al.

2005; Farquhar 1987;

Geng et al. 2010;

Xutian et al. 2009)

\begin{tabular}{|c|c|c|c|}
\hline $\begin{array}{l}\text { AMED, } \\
\text { MEDLINE \& } \\
\text { Alt Health } \\
\text { Watch } \\
\text { (searched } \\
\text { together } \\
\text { through } \\
\text { EBSCO) } 1\end{array}$ & $\begin{array}{l}\text { (Chinese medicine } \\
\text { OR TCM) AND } \\
\text { (fertility OR } \\
\text { infertility OR } \\
\text { reproduct*) AND }^{*} \text { (sperm OR egg }_{\text {OR ooctye OR }} \\
\text { ovarian reserve } \\
\text { OR premature } \\
\text { ovarian failure } \\
\text { OR oligospermia } \\
\text { OR aspermia OR } \\
\text { azoospermia) }\end{array}$ & $25 / 04 / 11$ & $\begin{array}{l}10 \text { (Heese 2006; } \\
\text { Deadman 2008; } \\
\text { Clavey 2003; Qian } \\
\text { 1997) }\end{array}$ \\
\hline
\end{tabular}


Appendix 1 (cont.)

\begin{tabular}{|c|c|c|c|}
\hline Database & Search terms & $\begin{array}{l}\text { Date of } \\
\text { search }\end{array}$ & $\begin{array}{l}\text { Total results } \\
\text { (articles included) }\end{array}$ \\
\hline $\begin{array}{l}\text { AMED, } \\
\text { MEDLINE \& } \\
\text { Alt Health } \\
\text { Watch } \\
\text { (searched } \\
\text { together } \\
\text { through } \\
\text { EBSCO) } 2\end{array}$ & $\begin{array}{l}\text { (jing or essence) } \\
\text { AND Chinese } \\
\text { medicine }\end{array}$ & & $\begin{array}{l}46 \text { (Hammer 1999; } \\
\text { Magidoff 2000; } \\
\text { Magidoff 1999; } \\
\text { Farquhar 1987; Larre } \\
\text { and Rochat de la } \\
\text { Vallee 2002; Xutian } \\
\text { et al. 2009; Scheid } \\
\text { 2005; Zheng 1997) }\end{array}$ \\
\hline $\begin{array}{l}\text { Journal of } \\
\text { Chinese } \\
\text { Medicine }\end{array}$ & $\begin{array}{l}\text { Manual Search } \\
\text { 'Jing essence sperm } \\
\text { egg' }\end{array}$ & $27 / 04 / 11$ & $\begin{array}{l}6 \text { (Buck et al. 2000; } \\
\text { Clavey 2003; Heese } \\
\text { 2006; Deadman } \\
\text { 2008; Qian } \text { et al. } \\
\text { 2010 [JTCM]; } \\
\text { Zhang } 2007 \text { [JTCM]) }\end{array}$ \\
\hline The Lantern & $\begin{array}{l}\text { Manual Search } \\
\text { 'Jing, essence, } \\
\text { sperm, egg' (various } \\
\text { combinations) }\end{array}$ & $27 / 04 / 11$ & $\begin{array}{l}3 \text { (Xingzhe 2004; } \\
\text { XIngzhe 2004a; } \\
\text { Zelicha and Nuria } \\
2010 \text { ) }\end{array}$ \\
\hline $\begin{array}{l}\text { European } \\
\text { Journal of } \\
\text { Oriental } \\
\text { Medicine }\end{array}$ & $\begin{array}{l}\text { Manual Search } \\
\text { 'Jing, essence, } \\
\text { sperm, egg' (various } \\
\text { combinations) }\end{array}$ & $27 / 04 / 11$ & $\begin{array}{l}1 \text { (Larre and Rochat } \\
\text { de la Vallee 2002) }\end{array}$ \\
\hline $\begin{array}{l}\text { www.itmonline } \\
\text {.com }\end{array}$ & $\begin{array}{l}\text { Manual Search } \\
\text { 'Jing, essence, } \\
\text { sperm, egg' (various } \\
\text { combinations) }\end{array}$ & $27 / 04 / 11$ & $\begin{array}{l}1 \text { (Dharmananda } \\
\text { n.d.) }\end{array}$ \\
\hline $\begin{array}{l}\text { British Library } \\
\text { [www.bl.uk] }\end{array}$ & $\begin{array}{l}\text { Chinese medicine } \\
\text { AND infertility OR } \\
\text { fertility OR jing OR } \\
\text { essence, OR ovarian } \\
\text { reserve }\end{array}$ & $27 / 07 / 11$ & $\begin{array}{l}31 \text { (Lyttleton 2004; } \\
\text { Lewis 2004; Larre } \\
\text { and Rochat de la } \\
\text { Vallee1999; } \\
\text { Unschuld 1986; } \\
\text { Unschuld 2003) }\end{array}$ \\
\hline
\end{tabular}


Appendix 1 (cont.)

\begin{tabular}{|c|c|c|c|}
\hline Database & Search terms & $\begin{array}{l}\text { Date of } \\
\text { search }\end{array}$ & $\begin{array}{l}\text { Total results } \\
\text { (articles included) }\end{array}$ \\
\hline $\begin{array}{l}\text { General } \\
\text { internet search }\end{array}$ & $\begin{array}{l}\text { 'ovarian reserve, } \\
\text { jing, Chinese } \\
\text { medicine' (various } \\
\text { combinations) }\end{array}$ & $27 / 04 / 11$ & $\begin{array}{l}6 \text { (Brown 2009; Lewis } \\
\text { 2011; Lewis 2011a; } \\
\text { Horne 2011; Brown } \\
\text { 2011; West 2011) }\end{array}$ \\
\hline
\end{tabular}

\section{Appendix 2: Extended quotations and definitions of $j i n g$}

\section{Huang Di Nei Jing Su Wen, Chapter 1}

'When a girl is fourteen, she comes into her prenatal vitalities [tiangui], her controller vessel moves and her thoroughfare vessel is abundant; her menses flow regularly and she is able to bear children.... When [a boy] is sixteen, his kidney $q i$ is abundant and he comes into his prenatal vitalities. His seminal essence overflows and drains; he is able to unite yin and yang and so beget young'. (translated by Wu 2010, p. 90)

Nan Jing (Difficult Issue 36)

'(1) Each of the depots is a single [entity], except for the kidneys which represent a twin [entity]. Why is that so?

(2) It is like this. The two kidneys are not both kidneys. The one on the left is the kidney; the one on the right is the gate of life. (3) The gate of life is the place where the spirit-essence lodges; it is the place to which the original influences are tied. (4) Hence, in males it stores the essence; in females it holds the womb. (5) Hence one knows there is only one kidney.' (translated by Unschuld 1986)

World Health Organisation 2007

1.2.1 essence 精 (1) the fundamental substance that builds up the physical structure and maintains body function; (2) reproductive essence stored in the kidney

1.2.2 innate essence 先天之精 the original substance responsible for construction of the body and generation of offspring, often referring to the reproductive essence, also called prenatal essence

1.2.3 acquired essence 後天之精 the essential substance acquired from the food after digestion and absorption, and used to maintain the vital activities and metabolism of the body, the same as postnatal essence

1.2.4 kidney essence 腎精 the original essence stored in the kidney 
Wiseman and Feng 1998

'Essence 精 jing: That which is responsible for growth, development, and reproduction, and determines the strength of the constitution, and is manifest physically in the male in the form of semen. Essence is composed of earlier heaven essence (congenital essence) which is inherited from the parents and constantly supplemented by later heaven essence (acquired essence) produced from food by the stomach and spleen.'

\section{Maciocia 2005}

'Jing is said to be stored by the Kidneys (with which it has a close relationship), and controls birth, growth, reproduction and general constitutional strength.'

\section{Sivin 1987}

'The Ching is the foundation of life; it is a fundamental substance that shapes the human body and maintains every kind of vital activity, directly affecting growth, development, aging, and death.'

\section{Shanghai College of Traditional Medicine 1981}

'Essence (a Yin characteristic) is that aspect of the body which is the basis for all growth, development and sexuality. Congenital Essence is that part of the body's Essence which is inherited from the parents. After birth this Essence, which is akin to an inborn constitution, determines each of our growth patterns. Congenital Essence can never be replaced if lost, but can be supplemented by acquired Essence, which is derived from food. Essence also has the narrow meaning of semen.'

Dharmananda n.d.

'Jing is the Chinese designation for the essential fluid of our physical body.... The basic yin (matter) from which all yang (physical action) springs is jing. In classical Chinese medical texts, jing is sometimes referred to as the body's "original water" with water representing the ultimate yin ("original fire" being the ultimate $y a n g) . .$. Although the word jing is synonymous with the Chinese word semen, the seminal fluid represents only one form of jing. Other dense fluid essences such as saliva (particularly the kind that gets spontaneously excreted during meditation), vaginal fluids, breast milk or blood are all regarded to be different transformations of one and the same jing; these are refined essences.' 
Kaptchuk 2000

'The texture most closely associated with life itself; it is the source of life and its unfolding.... It is the texture that gives organic life its specific character. It is the stuff of growth and development. Essence is the potential for differentiation into life's Yin and Yang. Essence, in one form or another, is the primordial seed of the life process, the life process itself, and life's final fruit.' 